\title{
Developing Cholinergic Basal Forebrain Neurons Are Sensitive to Thyroid Hormone
}

\author{
Elizabeth Gould ${ }^{\mathrm{a}}$ and Larry L. Butcher \\ Laboratory of Chemical Neuroanatomy, Department of Psychology, University of California, Los Angeles, California 90024
}

The influence of thyroid hormone on the development of cholinergic neurons in nucleus basalis was assessed in hyperthroid, hypothyroid, and euthyroid rats by use of CAT immunohistochemistry and single-section Golgi-impregnation histology. Animals were made either hyperthyroid by daily injections of $1.0 \mu \mathrm{g} / \mathrm{gm}$ body weight triiodothyronine starting at postnatal day (P) 3 or hypothyroid by providing $0.4 \%$ propylthiouracil in the diet of dams from P2. Compared to developing control rats, increased exposure to thyroid hormone resulted in accelerated expression of CAT in nucleus basalis neurons. Overshoot in cell body size, a normal developmental phenomenon of cholinergic neurons in the basal nuclear complex, occurred earlier in hyperthyroid brains and was of a greater magnitude than in controls. Furthermore, increased numbers of primary dendrites and dendritic branchpoints accompanied by dendritic and perisomal filopodia-like structures were observed for nucleus basalis neurons in hyperthyroid rats. These dendritic changes persisted throughout the second postnatal month. After the fifth postnatal week, cell body sizes of these hyperthyroid CAT-positive neurons began to decrease and by P50 were significantly less than controls or similarly treated animals at earlier ages. By P64, the number of cholinergic neurons in nucleus basalis was appreciably less than in age-matched controls.

Hypothyroidism resulted in a delay of normal CAT expression that persisted throughout the third postnatal week. After this time, CAT staining increased until normal immunoreactivity was attained in cell bodies, fibers, and terminal regions by P35. A deficit in thyroid hormone during development prevented overshoot in perikaryal size and resulted in diminished cross-sectional areas throughout the cholinergic nucleus basalis at all ages examined. Hypothyroidism also prevented the normal overproduction of dendrites in those cells and produced stunted dendritic trees at all ages examined. These morphological abnormalities persisted throughout the second postnatal month.

The effects of thyroid hormone on cholinergic projection neurons in the rat brain appeared relatively selective for cells in the basal nuclear complex because neither hypothyroid nor hyperthyroid treatment produced changes in the cell body

Received Sept. 30, 1988; revised Feb. 6, 1989; accepted Mar. 22, 1989.

This research was supported by USPHS grant NS10928 to L.L.B. Predoctoral support for E.G. was provided by NIMH training grant MH 15795.

Correspondence should be addressed to Larry L. Butcher at the above address.

a Present address: Laboratory of Neuroendocrinology, The Rockefeller University, 1230 York Avenue, New York, NY 10021.

Copyright (C) 1989 Society for Neuroscience 0270-6474/89/093347-12\$02.00/0 areas of the phenotypically similar CAT-positive neurons of the pontomesencephalotegmental complex.

The present findings suggest that thyroid hormone stimulates the developmental expression of CAT in nucleus basalis. Additionally, thyroid hormone appears to be necessary for the normal morphological development of those cells. A deficit in thyroid hormone yields cholinergic neurons with small somata and stunted, abnormally shaped dendrites. An excess of thyroid hormone produces cell body hypertrophy and increased dendritic growth. This acceleration of normal developmental processes combined with continued treatment leads eventually to signs of degeneration and cell death in this neuronal population.

It is now generally accepted that thyroid hormone plays a critical role in the development of several species (Kaltenbach, 1953; Kollros and McMurray, 1956; Eayrs, 1964; Sokoloff, 1977). A deficit or an excess of thyroid hormone during critical periods of development leads to profound and permanent biochemical (Kalaria et al., 1981; Kalaria and Prince, 1985a, b) and morphological (Rami et al., 1986; Ipina et al., 1987) abnormalities in the mammalian nervous system. Biochemical evidence suggests that developing forebrain cholinergic neurons are sensitive to thyroid hormone. The thyroid hormone 3,5,3'-triiodothyronine (T3) has been demonstrated to increase the cholinergic synthetic enzyme CAT (EC 2.3.1.6) in cultures of whole brain (Honegger and Lenoir, 1980; Atterwill et al., 1984), telencephalon (Honegger and Lenoir, 1980; Honegger, 1983), and medial septum (Hefti et al., 1986; Hayashi and Patel, 1987). Furthermore, thyroid hormone treatment significantly increases CAT in the developing basal forebrain in vivo (Patel et al., 1988), and hypothyroidism has been demonstrated to decrease levels of CAT in developing whole brain (Valcana, 1971; Kalaria et al., 1981), striatum (Kalaria and Prince, 1985a), and the basal forebrain and its targets, the neocortex and hippocampus (Patel et al., 1987). Although these studies indicate that cholinergic forebrain systems are biochemically sensitive to thyroid hormone, it is not known if morphological features of basal forebrain neurons are influenced by thyroid hormone as well. In addition, it is at present unknown if other central cholinergic neurons, such as those of the pontomesencephalotegmental (PMT) complex (Woolf and Butcher, 1986), are similarly responsive to thyroid hormone. To determine if thyroid hormone affects the histochemical expression of CAT, as well as the morphological characteristics of developing basal forebrain and PMT neurons, CAT immunocytochemical and single-section Golgi analyses were performed on brain sections from hypothyroid, hyperthyroid, and euthyroid rats. 


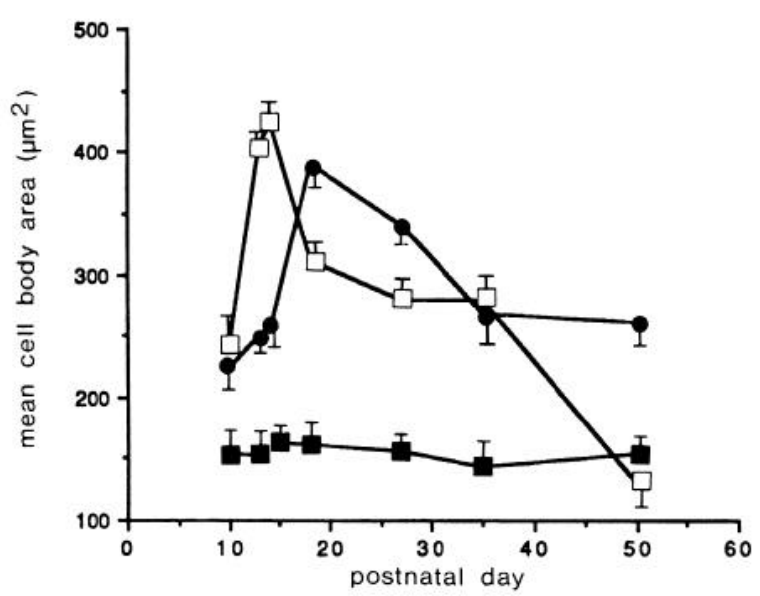

Figure 1. Perikaryal areas of CAT-positive neurons in nucleus basalis

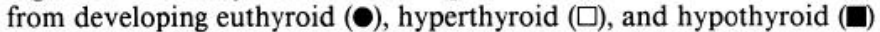
rats. Each graph point indicates the mean \pm SEM of data from 4 animals. Data from P64 rats are not indicated in this figure because declining numbers of cells in the hyperthyroid groups (see Figs. 4, 5) rendered meaningful comparisons statistically inappropriate.

\section{Materials and Methods}

Experimental animals and pharmacological manipulations. On the day of birth (P1), rat pups from 18 litters were pooled, and 8 pups were distributed to each dam. Pups of 6 of those litters served as no-treatment controls. Animals of another 6 litters were made hyperthyroid by daily subcutaneous injections of $1.0 \mu \mathrm{g} / \mathrm{gm}$ body weight T3 (see Meaney et al., 1987) from P3 until the day of perfusion. Pups of the final 6 litters were made hypothyroid by providing $0.4 \%$ propylthiouracil (PTU) in the diet of the dams, as described by Kalaria and Prince (1985a), from P2 until the day of perfusion. PTU was provided in the food of the dams because it readily enters the milk (see Kalaria and Prince, 1985b), and oral administration is behaviorally less disruptive than injection or intubation of either the pups or dams. In addition, PTU treatment was initiated $1 \mathrm{~d}$ before T3 injections because of the indirect route of drug application in the former method (i.e., first to dam and then to pup).

On P10,13,14,18,27,35, 50, and 64, rats from each of the groups were perfused. They were first deeply anesthetized with $350 \mathrm{mg} / \mathrm{kg}$ chloral hydrate, placed on ice, and then transcardially perfused with 50 ml PBS (pH 7.4), followed by 50 to $250 \mathrm{ml} 4 \%$ paraformaldehyde containing $0.2 \%$ picric acid. Brains were dissected from the cranial cavities and postfixed in a solution having the same composition as the above-described perfusate for $2 \mathrm{~d}$ before being processed for singlesection Golgi impregnation (Gabbott and Somogyi, 1984) or CAT immunohistochemistry according to an avidin-biotin procedure described previously (Gould and Butcher, 1987) and outlined here.

CAT immunohistochemistry. Sections, $50 \mu \mathrm{m}$, were cut using a vibratome and incubated for $24 \mathrm{hr}$ at room temperature in a solution of a monoclonal antibody against CAT (code 11/255; for characterization see Eckenstein and Thoenen, 1982) diluted 1:50 in PBS containing sodium azide. After rinsing in PBS, the sections were incubated for 2 $\mathrm{hr}$ in biotinylated rabbit antirat IgG with diluted rabbit normal serum (1:80 in PBS). After subsequent rinsing in PBS, the sections were incubated for an additional $2 \mathrm{hr}$ in a solution of biotin-avidin-peroxidase complex. They were then rinsed in PBS and reacted for 15 to $20 \mathrm{~min}$ in diaminobenzidine and $\mathrm{H}_{2} \mathrm{O}_{2}$ containing $2.5 \%$ nickel ammonium sulfate. Sections were then rinsed in PBS, mounted on gelatinized slides, dehydrated, and coverslipped under Permount. As controls, some sections were processed as described above but without the primary antibody.

To maximize the reliability of staining intensity comparisons within and between animals, CAT immunohistochemistry was performed simultaneously on forebrain and brain-stem tissue from brains of each age across all treatment groups. In all cases in which immunohistochemistry was performed on tissue sections from pharmacologically treated brains, control sections of the same age were processed at the same time. In addition, all immunohistochemical procedures, including incubation and postfixation times and the interval between perfusion
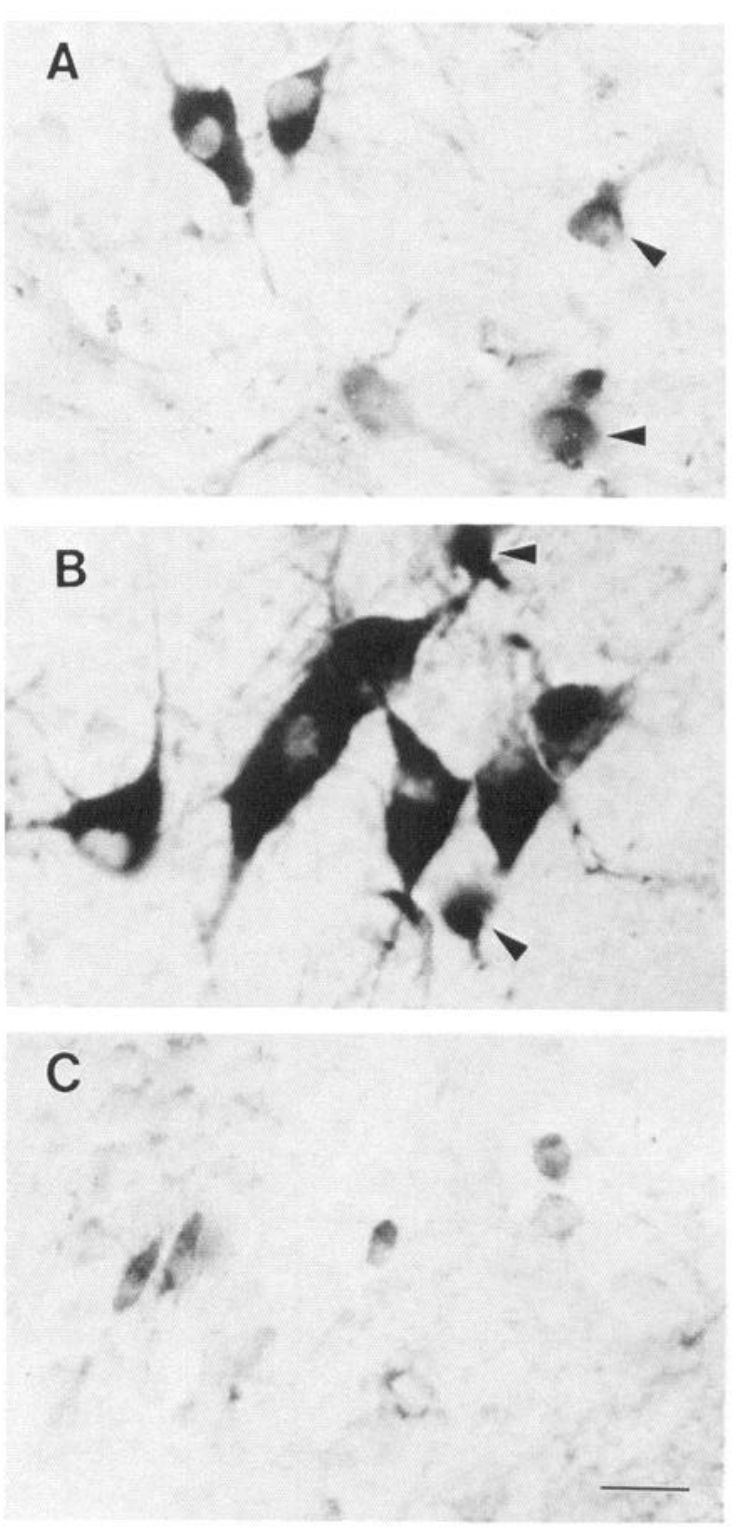

Figure 2. CAT-immunoreactive neurons in nucleus basalis from control $(A)$, hyperthyroid $(B)$, and hypothyroid $(C)$ rats at age P14. These brain sections were incubated simultaneously to provide valid and reliable comparisons among the treatment conditions. In relation to the euthyroid cells shown in $A$, observe the generally increased immunoreactivity and soma sizes of neurons in $B$ and the comparatively light staining and smaller cross-sectional areas of the perikarya in $C$. Arrowheads point to comparably sized neurons or neuron fragments in $A$ and $B$. Compare with corresponding neurons in Figure 3. Scale bar in $C$ equals $30 \mu \mathrm{m}$ and applies to all frames.

and subsequent processing, were standardized to minimize interpretive errors in comparisons between different brains. Analyses of immunoreactivity were always performed on randomly selected tissue sections.

Before quantitative analysis, the slides containing tissue immunohistochemically processed for CAT were coded, and the code was not broken until measurements were completed. Brain sections throughout the nucleus basalis (see Bigl et al., 1982, and Mesulam et al., 1983, for neuroanatomical boundaries of this cellular configuration) were selected randomly from each of four brains in each treatment group for each age examined. For each selected brain section, the cross-sectional areas of CAT-positive somata in the nucleus basalis were determined by use of a microscope drawing tube (camera lucida) and a Zeiss Interactive Digitizing Analysis System (see Gould et al., 1989). Statistical means of this variable were calculated for each animal for each age and treatment 


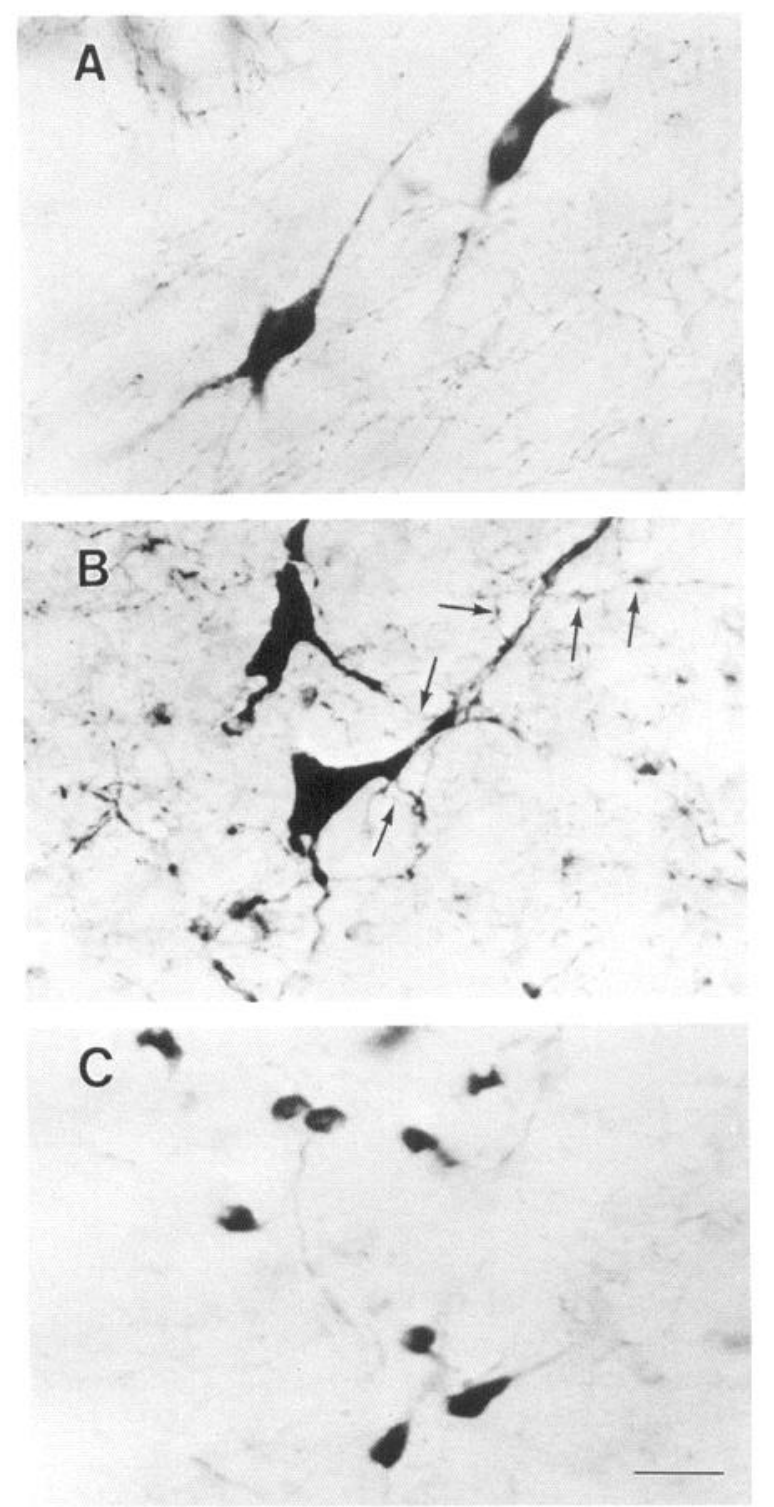

Figure 3. CAT-positive neurons in nucleus basalis from control $(A)$, hyperthyroid $(B)$, and hypothyroid $(C)$ rats at age $\mathrm{P} 35$. Tissue sections were incubated simultaneously to provide valid and reliable comparisons among treatment conditions. Observe the essentially identical intensity of CAT staining in all frames, with the possible exception of slightly increased immunoreactivity in $B$. Note the substantially smaller cell body sizes in $C$ compared to $A$. Arrows in $B$ indicate dendritic outgrowths. Scale bar in $C$ equals $30 \mu \mathrm{m}$ and applies to all frames.

group, and these data were evaluated by two-way analyses of variance (age vs treatment) with post hoc comparisons of individual means (Hays, 1981). Measurements of the cell body areas of CAT-positive neurons in the PMT complex from hypothyroid, euthyroid, and hyperthyroid brains were performed according to the same procedure and were subjected to the same statistical analyses. Tissue processed for CAT immunohistochemically was then qualitatively analyzed with the use of a light microscope for cell body size and shape, number of dendrites, and intensity of immunoreaction product in the nucleus basalis and the pontomesencephalic tegmentum. To assess relative intensity of CAT immunoreactivity, sections that were processed simultaneously from different treatment groups of the same age were examined so that reliable comparisons could be made. The number of CAT-positive neurons on randomly selected sections throughout the nucleus basalis was determined by use of a drawing tube and a low-power microscope.

Golgi-impregnation histology. Brains from P1 8 and P35 hyperthryoid,

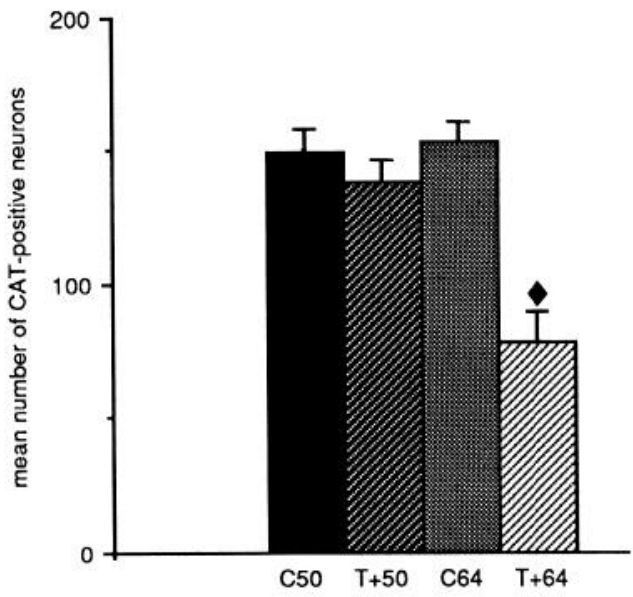

Figure 4. Number of CAT-positive neurons at one level of nucleus basalis for P50 euthyroid (C50) and hyperthyroid (T+50) and P64 euthyroid (C64) and hyperthyroid $(\mathrm{T}+64)$ rats. Values represent the mean \pm SEM of data from 8 animals in the C50, C64, and T +64 groups and 3 rats in the $T+50$ group. Diamond indicates statistically significant difference from C64 control $(p<0.01)$. In Nissl-stained material, a $38 \%$ loss of somata was observed in $\mathrm{T}+64$ rats compared to $\mathrm{C} 64$ controls $(p<0.0005)$.

hypothyroid, and euthyroid animals were processed according to the single-section Golgi procedure of Gabbott and Somogyi (1984). These days were selected because significant dendritic changes occur in the normal basal forebrain at this time (Butcher et al., 1988; Gould et al., 1989). Sections, $100 \mu \mathrm{m}$ thick, were cut in a bath of $3 \%$ potassium dichromate in distilled deionized water and collected into a Petri dish containing the same solution. After $24 \mathrm{hr}$, the sections were removed, rinsed in distilled deionized water, and mounted onto glass slides. Coverslips were placed over the tissue and glued at the corners with cyanoacrylate. The slides were then placed into Coplin jars filled with $1.5 \%$ silver nitrate and stored in the dark for $48 \mathrm{hr}$. The coverslips were removed, and the sections were rinsed in distilled deionized water before being mounted out of $2 \%$ potassium dichromate onto gelatinized slides. The tissue was dehydrated in absolute ethanol, cleared in methylsalicylate followed by xylene for $5 \mathrm{~min}$, and coverslipped under Permount.

In order to qualify for quantitative analysis, Golgi-impregnated neurons had to possess the following characteristics: (1) location within the nucleus basalis (see Bigl et al., 1982; Mesulam et al., 1983), (2) dark and consistent staining reaction throughout all dendrites, (3) a cell body in the middle third of the tissue section to avoid analysis of neurons extending largely into adjacent sections, and (4) morphological features consistent with those currently believed to be shared by cholinergic neurons. These criteria were formulated from data in several studies from our laboratory and others, using the methods of CAT immunohistochemistry (Butcher et al., 1985), Golgi impregnation (Kristt et al., 1985; Brauer and Winkelmann, 1987; Butcher et al., 1988; Dinopoulos et al., 1988), and combined Golgi impregnation and CAT immunohistochemistry on the same tissue section (Gorman et al., 1987) to examine basal forebrain cholinergic neurons. These features included a large cell body ( $>20 \mu \mathrm{m}$ in maximum soma extent), multiple ( 3 or more) aspiny or sparsely spined dendrites, and, in some instances, varicose axons and dendrites. The selection of appropriate Golgi-impregnated nucleus basalis neurons from hyperthyroid and hypothyroid brains for analysis required familiarity with the morphological characteristics of nucleus basalis CAT-positive neurons in all treatment groups at P18 and P35. For pharmacologically manipulated brains, these features were drawn primarily from our qualitative and quantitative analysis of CAT immunohistochemical tissue with reference to the previously mentioned studies performed on control brains. Slides containing Golgi-stained basal forebrain tissue were not coded for blind analyses because the selection of individual neurons required reference to CAT immunohistochemical tissue from the appropriate age and treatment groups.

On the basis of the foregoing criteria, 192 Golgi-impregnated neurons were selected from four P18 and four P35 hyperthryoid, four P18 and four P35 hypothyroid, and four P18 and four P35 control brains. Each Golgi-impregnated neuron was quantitatively analyzed for the number 

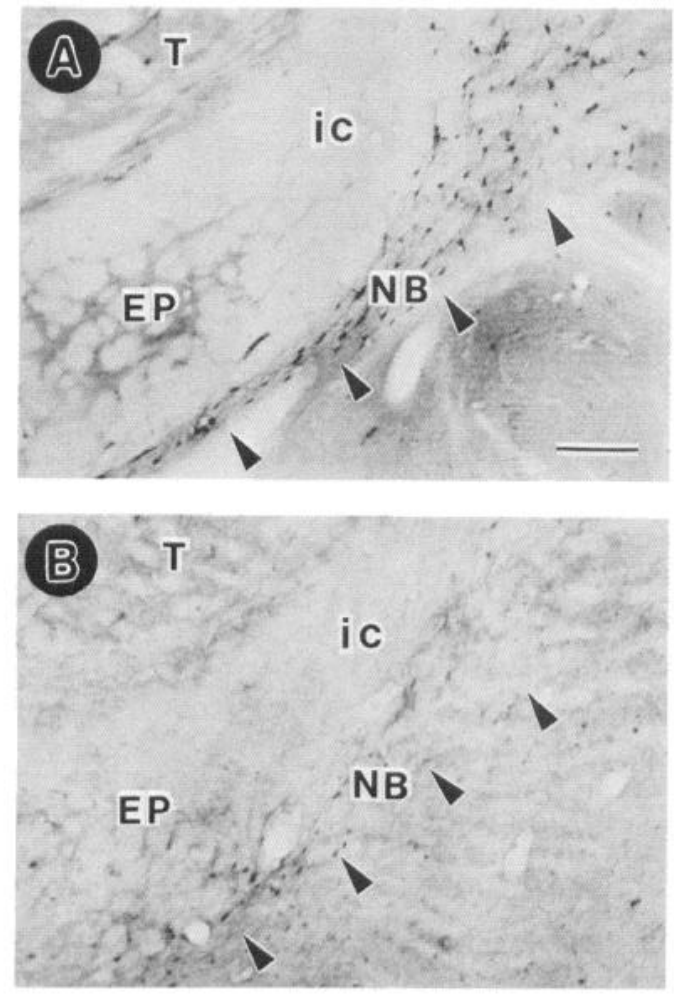

Figure 5. Loss of CAT-positive neurons in the nucleus basalis $(N B$ arrows) of a P64 rat given daily injections of T3 from P3 until death ( $B$, compare with age-matched euthyroid brain in $A$ ). Scale bar in $A$ is $100 \mu \mathrm{m}$ and applies also to $B$. $E P$, entopeduncular nucleus; $i c$, internal capsule; $T$, thalamus.

of primary dendrites, the number of dendritic branch points, and the length of the longest dendrite. This last measurement was made on dendrites that were straight. Results were statistically evaluated as described for CAT-positive neurons.

\section{Results}

\section{Hyperthyroidism and hypothyroidism: general observations}

The effects of thyroid hormone administration became obvious during the second postnatal week. Whereas control rat pups showed fully opened eyes by P14, all hyperthryoid rat pups demonstrated fully opened eyes as early as P10. In addition, hyperthyroid animals were larger in size than controls and possessed other physical characteristics, such as larger teeth and coarser hair, that were more commonly observed in older control animals. From P35 through P64, the oldest age examined, hyperthyroid animals were noticeably smaller than age-matched controls. Several distinctive behavioral characteristics were also noted for rats treated with thyroid hormone. During the second postnatal week, hyperthyroid rat pups showed increased exploratory behavior, increased arousal to auditory stimuli, and a very pronounced tremor compared to age-matched controls. Hyperthyroid animals were also observed eating rat chow as early as P14 but remained with the dam until the time of normal weaning (P22).

The effects of the hypothyroid-inducing drug were apparent from the second postnatal week onward. Hypothyroidism resulted in significantly smaller body sizes than age-matched controls for animals at age P14 and older that persisted throughout the second postnatal month. In addition, most hypothyroid animals did not show fully opened eyes until the fourth postnatal

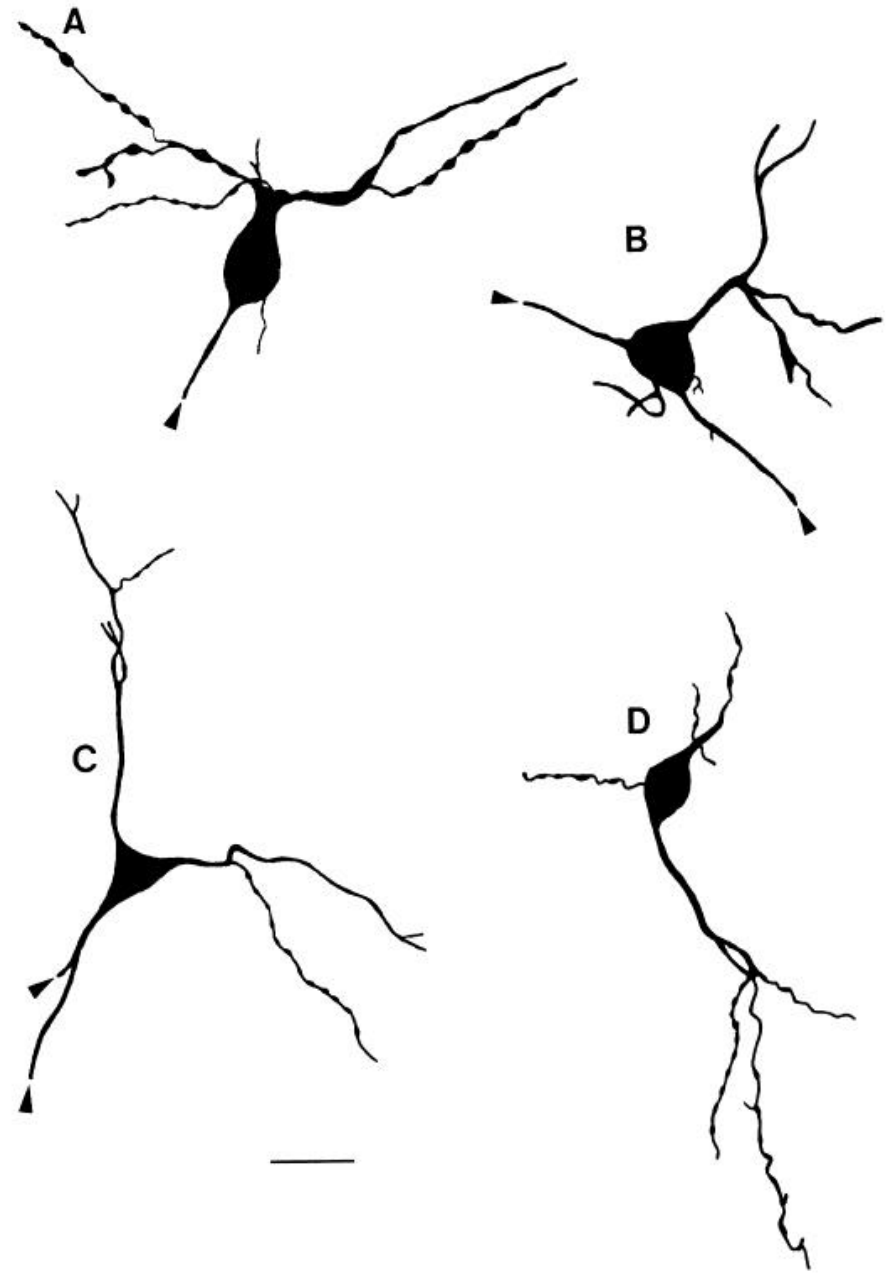

Figure 6. Camera lucida drawings of Golgi-impregnated neurons from the euthyroid nucleus basalis. Cells from P18 brains are depicted in $A$ and $B$, and those from P35 brains are shown in $C$ and $D$. Arrowheads indicate cut dendrites. Scale bar is $30 \mu \mathrm{m}$ and applies to all neurons.

week (P28). Hypothyroid animals also demonstrated immature physical characteristics, such as small teeth, a rounded face, undeveloped external ears, and soft, fine hair. Hypothyroid animals were not weaned at the end of the third postnatal week. These pups remained with the dam throughout the second postnatal month. Hypothyroidism also resulted in a number of obvious behavioral abnormalities, including decreased arousal to auditory stimuli, decreased exploratory behavior, and motor incoordination.

\section{CAT immunohistochemistry}

Immunohistochemical controls revealed an absence of nonspecific immunoreactivity of the secondary antibody in all experimental groups. The results of other controls for the specificity of the immunohistochemical procedure for CAT have been described in numerous previous publications from this laboratory (Woolf and Butcher, 1986; Gould and Butcher, 1987; Woolf et al., 1989).

Light microscopic examination of CAT-positive neurons in the developing nucleus basalis of untreated rats corroborated our previous findings on normal animals (Butcher et al., 1988; Gould et al., 1989). The somata of CAT-positive basal forebrain neurons of control brains steadily increased in size during the 

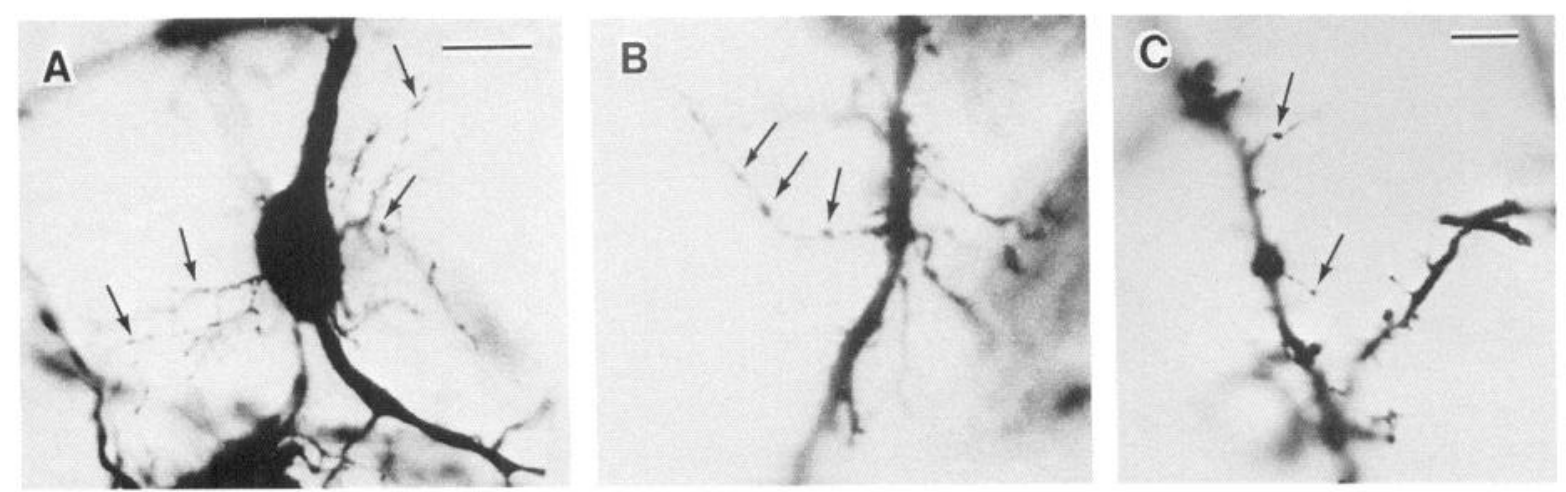

Figure 7. Golgi-impregnated neurons in the nucleus basalis from $\mathrm{P} 18(A)$ and $\mathrm{P} 35(B, C)$ hyperthyroid brains in a single plane of focus. The entire extents of these neurons in a single brain section, designated by the same letters, are shown in Figure 8. Arrows point to proliferative morphological profiles not typically encountered in these cells (compare with corresponding neurons in Fig. 6). Scale bar in $A$ is $20 \mu \mathrm{m}$. Scale bar in $C$ is $15 \mu \mathrm{m}$ and applies also to $B$.

early postnatal period to P18, after which they underwent cell body shrinkage until adult soma sizes were reached by P35 (Fig. 1). During this period of increasing perikaryal area, CAT immunoreactivity also increased in intensity. Neurons of the P10, P13, P14, and P18 basal forebrains of hyperthyroid rats, however, were generally more intensely immunoreactive for CAT than those of age-matched controls (Fig. $2 B$, compare with $A$ ). By P27 and through P35, however, control basal forebrain neurons attained levels of CAT immunoreactivity that were comparable to hyperthyroid brains (Fig. 3, $B$, compare with $A$ ). Normal CAT-positive neurons at all ages examined were relatively large and multipolar (e.g., Figs. $2 A, 3 A$ ).

Statistical analyses of the cell body areas of euthyroid, hyperthyroid, and hypothyroid basal forebrain neurons during development demonstrated a significant relationship between age and treatment condition $[\mathrm{F}(10,54)=110.9, p<0.0001]$. Quantitative analyses of CAT-positive neurons in the nucleus basalis of hyperthyroid animals showed that cell body hypertrophy was reached at an earlier time than that observed in normal controls. In hyperthyroid animals, the maximum soma size occurred at the end of the second postnatal week, approximately $4 \mathrm{~d}$ before peak cell body size was reached in controls (Fig. 1). At P14, the peak cell soma size was also significantly greater $(p<0.0002)$ than the peak perikaryal size observed in P18 controls (Fig. 1). Thereafter, soma shrinkage occurred rapidly, and by P27, the perikaryal sizes of neurons in the nucleus basalis of hyperthyroid rats did not differ significantly from those in normal P35 animals (Fig. 1). Surprisingly, examination of CAT-positive basal forebrain neurons from hyperthyroid brains after P35 revealed a significant decrease in soma size compared to earlier developmental time periods (Fig. 1), and by P50, cross-sectional areas of these cells were not significantly different from those observed in the hypothyroid condition (Fig. 1). Although the distribution of nucleus basalis neurons in hyperthyroidism was comparable to age-matched control rats through P50 (Fig. 4), by the latest time period examined, $\mathrm{P} 64$, a significant decrease in the number of CAT-immunoreactive somata was observed in nucleus basalis (Figs, 4, 5).

Morphological profiles of CAT-positive neurons of the hyperthyroid basal forebrain varied throughout development. At P14, when maximal cell body size was noted in these neurons, CAT-positive cells from hyperthyroid brains resembled those of the control basal forebrain on P18. These neurons were most often round or oval in cell body shape (Fig. $2 B$ ). During the third and fourth postnatal weeks, as CAT-positive neurons were decreasing in cell body size, these neurons became more varied and complex in appearance. Many neurons retained their immature morphologies, showing round, globular cell bodies, whereas other neurons took on more complex cell body shapes (Fig. 3B). In many instances, CAT-positive hyperthyroid basal forebrain neurons possessed more dendrites, as well as dendrites with larger varicosities, than were observed for age-matched controls. Despite the reduction of CAT-positive neurons in nucleus basalis by $\mathrm{P} 64$, the remaining neurons continued to demonstrate increased numbers of dendrites coupled with a greater number of protuberances extending from both the cell body and dendrites. Many of these remaining cells had somata that appeared somewhat shriveled (see trend indicated in Fig. 1) and irregularly shaped.

Compared to euthyroid controls, CAT-positive neurons in the nucleus basalis of PTU-treated rats evinced significantly smaller soma areas at all ages examined (Figs. 1, 2C, 3C). The cell bodies of these neurons did not undergo hypertrophy at any age examined and remained significantly smaller throughout the second postnatal mounth (Figs. 1, 2C, 3C). Qualitative examination of hypothyroid brains showed a normal distribution of CAT-positive cells throughout the basal forebrain region that was comparable to age-matched controls at all ages examined. From P10 until P18, however, hypothyroid treated brains showed noticeably less CAT immunoreactivity within cell bodies, dendrites, and fibers when compared to euthyroid conditions (Fig. 2, $C$, compare with $A$ ). Beginning at P27 and definitely by P35, CAT-positive basal forebrain neurons from hypothyroid brains showed levels of immunoreactivity similar to those of agematched controls (Fig. 3, C, compare with $B$ ). Throughout development, fewer CAT-positive dendrites were noted for basal forebrain neurons from hypothyroid brains in comparison to controls (Fig. 3, $C$, compare with $B$ ). Aberrant dendritic profiles also were noted in nucleus basalis neurons, and many such CATpositive cells from PTU-treated rats possessed stump-like dendrites that extended only short distances with little, if any, branching. Those dendrites that did not appear to be abnormally formed possessed varicosities, which is also a characteristic of normal basal forebrain cholinergic neurons. These qualitative features of hypothyroid nucleus basalils neurons in hypothyroid animals were observed in the entire extent of the cholinergic basal nuclear complex.

Like cholinergic neurons in nucleus basalis, light microscopic 
Figure 8. Camera lucida drawings of the nucleus basalis neurons shown in part in Figure 7. Observe the extensive dendritic arbors and the perisomal and dendritic filopodia-like structures (compare with corresponding neurons in Fig. 6). Arrowheads point to cut dendrites. Scale bar is $30 \mu \mathrm{m}$ and applies to all neurons.
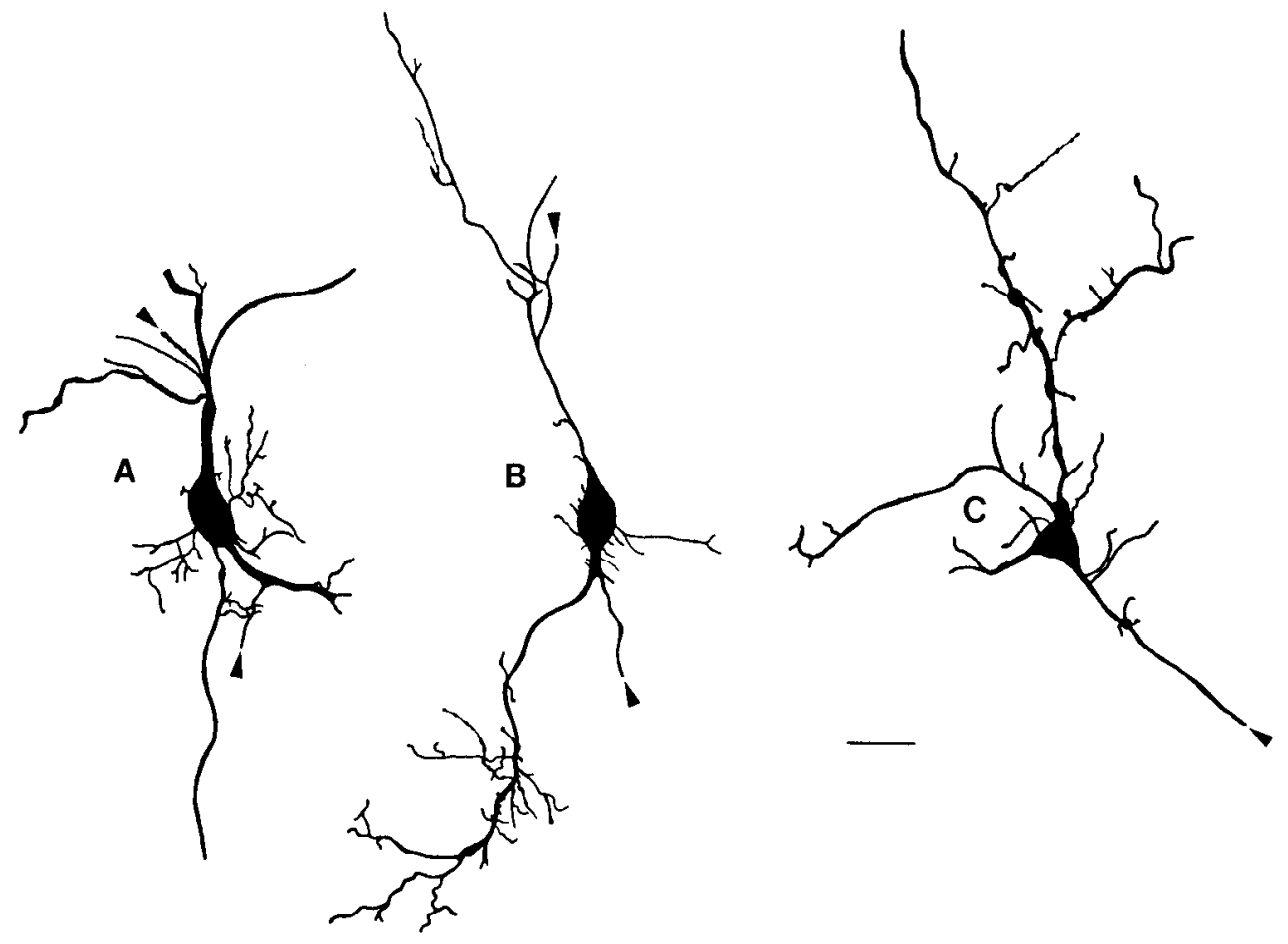

examination of CAT-positive cells of the euthyroid PMT complex corroborated previously obtained results on normal rats (Butcher et al., 1988). CAT-positive PMT neurons steadily increased in soma size until P13 (Table 1). Thereafter, PMT cholinergic neurons underwent a period of shrinkage, with the adult morphological profile being reached by the fourth postnatal week (Table 1). Neither hyperthyroid nor hypothyroid conditions resulted in significant alterations in CAT immunoreactivity at any age examined. Furthermore, quantitative analysis of cell body area of CAT-positive PMT neurons from hyperthyroid and hypothyroid brains showed no significant differences when compared to age-matched controls throughout postnatal development (Table 1). PMT cholinergic neurons of both treatment groups showed a steady increase in cell body size until P13 and then underwent a period of shrinkage. CAT-positive PMT neurons of hyperthyroid and hypothyroid brains were also morphologically indistinguishable from control CAT-positive neurons of the same age. In addition, no differences were seen in number or distribution of CAT-positive neurons throughout the PMT region with either treatment at any age examined.

\begin{tabular}{llll}
$\begin{array}{l}\text { Table 1. } \\
\text { complex }\end{array}$ & Mean cell body area of CAT-positive neurons in the PMT \\
& $\begin{array}{l}\text { Control } \\
\left(\mu \mathrm{m}^{2} \pm \text { SEM }\right)\end{array}$ & $\begin{array}{l}\text { Hyperthyroid } \\
\left(\mu \mathrm{m}^{2} \pm \text { SEM }\right)\end{array}$ & $\begin{array}{l}\text { Hypothyroid } \\
\left(\mu \mathrm{m}^{2} \pm \mathrm{SEM}\right)\end{array}$ \\
$\begin{array}{llll}\text { Postnatal } \\
\text { day }\end{array}$ & $n=4$ & $183.4 \pm 13.4$ & $190.2 \pm 21.3$ \\
\hline 10 & $185.3 \pm 11.5$ & $337.2 \pm 15.2$ & $340.7 \pm 20.1$ \\
13 & $323.4 \pm 24.3$ & $299.5 \pm 28.1$ & $300.9 \pm 19.3$ \\
18 & $300.5 \pm 20.1$ & $275.6 \pm 17.9$ & $264.0 \pm 25.0$ \\
27 & $276.3 \pm 13.8$ & $241.3 \pm 25.4$ & $249.2 \pm 21.9$ \\
35 & $254.3 \pm 10.9$ & $255.7 \pm 11.2$ & $252.3 \pm 23.8$ \\
50 & $265.9 \pm 19.8$ &
\end{tabular}

Means from treated animals are not significantly different from those of agematched controls.

\section{Golgi-impregnation histology}

Analyses of Golgi-impregnated nucleus basalis neurons possessing somatal profiles similar to CAT-positive cells from identically treated brains revealed some striking differences in the dendritic architecture in hyperthyroid rats compared to control animals. Such alterations were also seen occasionally in CATimmunoreactive tissue. By P18, Golgi-impregnated neurons of the basal forebrain with similar morphological features to CATpositive hyperthyroid neurons evinced more primary dendrites, more dendritic branchpoints, and longer dendrites than agematched controls (Figs. 5-11). Furthermore, short, fine dendritic or filopodia-like processes were observed extending directly from somata as well as from thicker primary and secondary dendrites (Figs. 7, 8). In some cases, these dendritic extensions could be traced up to $50 \mu \mathrm{m}$. These filopodia-like outgrowths were not evenly distributed along dendrites and, in some cases, were varicose (Figs. $7 B, 8$ ).

Quantitative analysis of Golgi-impregnated nuclcus basalis neurons of control brains corroborated previously reported findings on pharmacologically unmanipulated rats (Butcher et al., 1988). Normal neurons at P18 evinced significantly more primary dendrites and dendritic branchpoints than did P35 cells ( $p<0.0002$; see Figs. 9, 10 and 12,13), but the lengths of the longest dendrites were significantly shorter $(p<0.0005$; see Figs. $11,14)$. Statistical evaluation of $P 18$ and P35 brains indicated that, compared to age-matched controls, hyperthyroidism produced nucleus basalis neurons with significantly increased numbers of primary dendrites, increased numbers of dendritic branchpoints, and increased lengths of longest dendrites compared to age-matched controls (Figs. 9-11). Golgi-impregnated nucleus basalis neurons from hyperthyroid rats at age P35, however, were not significantly different $(p>0.05)$ with respect to these variables from basal nuclear cells of T3-treated animals at P18 (Figs. 12-14, compare with Figs. 9-11). Although no significant morphological changes occurred between P18 and 


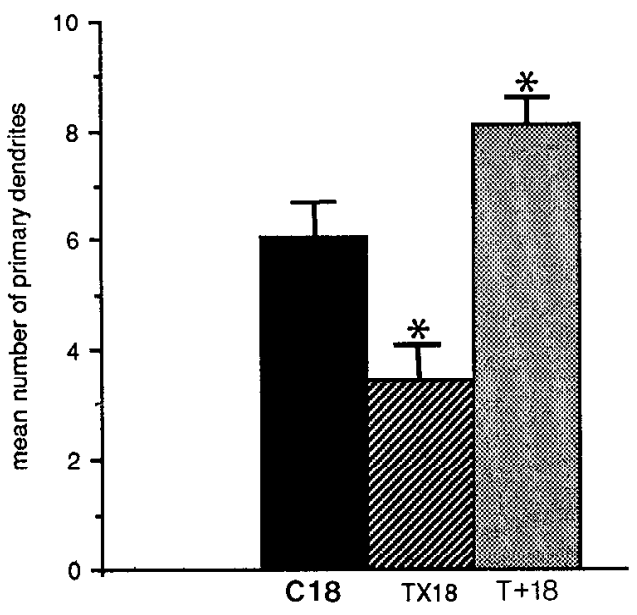

Figure 9. Effects of hypothyroidism (TX18) or hyperthyroidism $(\mathrm{T}+18)$ on number of primary dendrites in nucleus basalis neurons at age P18. Asterisks signify statistically significant difference $(p<0.001)$ from euthyroid control (C18). Each bar value is based on data from 4 animals. Vertical error lines indicate SEM.

P35 for hyperthyroid basal forebrain neurons, control neurons underwent dendritic length increases during this time to exceed those seen in T3-treated animals (Fig. 14, compare with Fig. 11). Nonetheless, the number of primary dendrites, as well as dendritic branchpoints, remained significantly higher than in controls in nucleus basalis neurons from hyperthyroid rats at age P35, as was the case in P18 animals (Figs. 12, 13, compare with Figs, 9, 10).

Light microscopic analysis of Golgi-impregnated tissue from PTU-treated brains at age P18 indicated the presence of many neurons throughout the basal forebrain resembling the small, predominantly round, CAT-positive neurons of the hypothyroid basal forebrain (Figs. 15B, 16B; compare with Fig. 3C). These cells also evinced dendritic profiles similar to those observed in tissue processed for CAT. Dendrites were thick relative to the cell body size and extended for short distances, with considerably less branching than seen in basal forebrain neurons

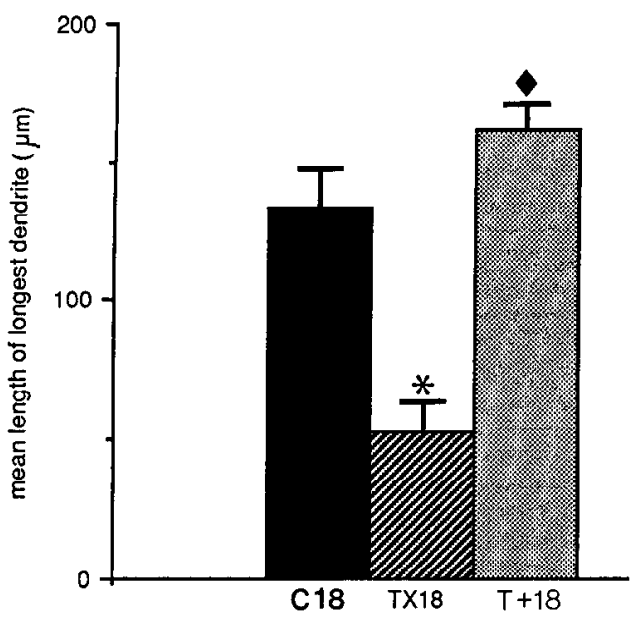

Figure 10. Effects of hypothyroidism (TX18) or hyperthyroidism $(T+18)$ on number of dendritic branchpoints in nucleus basalis neurons at age P18. Asterisks signify statistically significant difference $(p<0.001)$ from euthyroid control (C18). Each bar value is based on data from 4 animals. Vertical error lines indicate SEM.

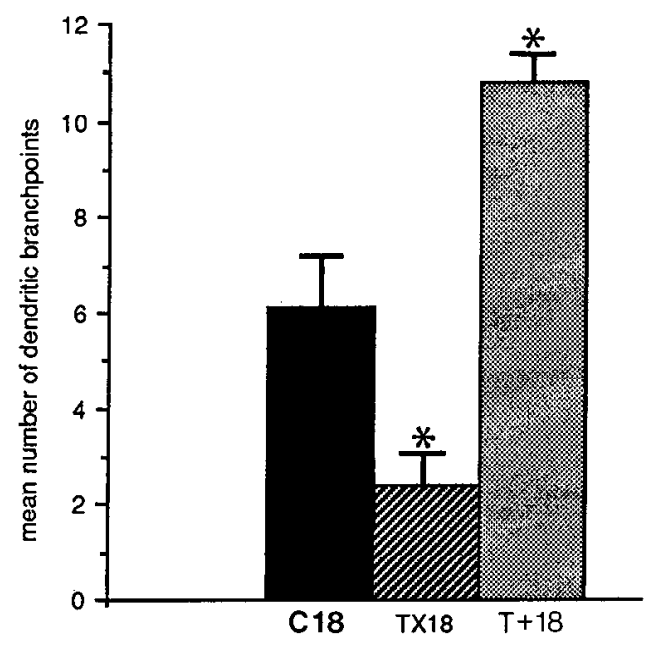

Figure 11. Effects of hypothyroidism (TX18) or hyperthyroidism $(T+18)$ on length of the longest dendrite in nucleus basalis neurons at age $\mathrm{P} 18$. Asterisk and diamond signify statistically significant difference ( $p<.0 .001$ and $p<0.05$, respectively) from euthyroid control (C18). Each bar value is based on data from four animals. Vertical error lines indicate SEM.

of untreated brains (Figs. 15, 16; compare with Fig. 6). The majority of Golgi-impregnated neurons from the nucleus basalis of hypothyroid rats demonstrated dendrites that tapered at the ends, suggesting that these cells were, in many cases, small enough to be present entirely within one $100 \mu \mathrm{m}$ section. This was not the usual case with nucleus basalis neurons from euthyroid and hyperthyroid brains. Processes of these latter cells frequently extended beyond the tissue section (Figs. 6, 8). Many of the dendrites that could be traced further on impregnated tissue did not extend in a linear fashion but, instead, seemed to twist in an aberrant, corkscrew-like fashion or possess abnormal protuberances (Figs. $15, B, C ; 16, B, C$ ). As observed in CATstained material from hypothyroid brains, Golgi-impregnated basal forebrain neurons showed dendritic varicosities, usually on those processes that appeared to be more normally formed

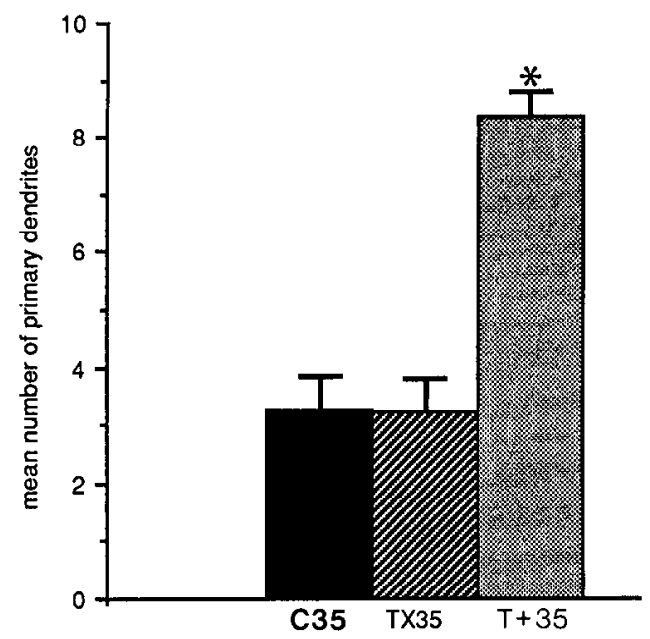

Figure 12. Effects of hypothyroidism (TX35) or hyperthyroidism $(\mathrm{T}+35)$ on number of primary dendrites in nucleus basalis at age P35. Asterisk signifies statistically significant difference $(p<0.001)$ from euthyroid control (C35). Each bar value is based on data from 4 animals. Vertical error lines indicate SEM. 


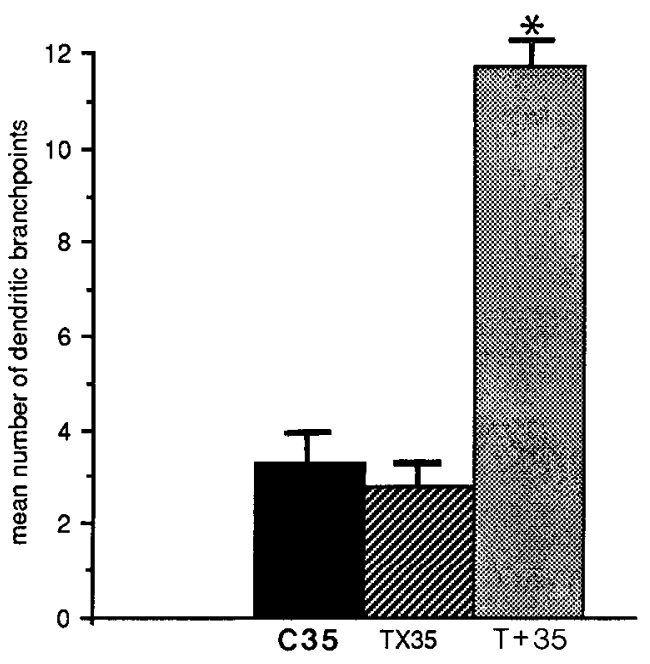

Figure 13. Effects of hypothyroidism (TX35) or hyperthyroidism $(\mathrm{T}+35)$ on number of dendritic branchpoints in nucleus basalis ncurons at age P35. Asterisk signifies statistically significant difference $(p<0.001)$ from euthyroid control (C35). Each bar value is based on data from 4 animals. Vertical error lines indicate SEM.

than others (Figs. 15A, 16A). Quantitative analysis of Golgiimpregnated nucleus basalis neurons indicated that P18 hypothyroid basal forebrain neurons possessed significantly fewer primary dendrites, fewer dendritic branchpoints, and shorter lengths of the longest dendrite than age-matched controls (Figs. 9-11), but these differences for the former 2 variables disappeared by $P 35$. The average length of the longest dendrite, however, was significantly shorter in the $\mathbf{P} 35$ hypothyroid basal forebrain in comparison to the P35 control (Fig. 14). The number of primary dendrites and branchpoints and lengths of the longest dendrite in P35 hypothyroid animals, however, were not significantly different $(p>0.05)$ from those in $\mathrm{P} 18$ hypothyroid rats (compare Figs. 12-14 with Figs. 9-11).

\section{Discussion}

Thyroid hormone effects on CAT expression

The results of this study indicate that developmental hyperthyroidism leads to an accelerated appearance of CAT immunoreactivity in basal forebrain neurons. Conversely, hypothyroidism results in delayed expression of CAT-like immunopositivity in those cells. These observations are compatible with biochemical findings demonstrating that hypothyroidism results in a decrease in CAT activity in vivo (Patel et al., 1987) and that thyroid hormone increases CAT activity both in vitro (Honegger, 1983; Hefti et al., 1986; Hayashi and Patel, 1987) and in vivo (Patel et al., 1988). Collectively, our results and those of the cited studies suggest that thyroid hormone stimulates basal forebrain neurons to synthesize CAT during development. Although hypothyroidism produced a delay in maximal CAT expression, immunorcactivity for that cnzymc appcarcd to increase in intensity and achieved levels of staining in cell bodies and fibers by P27 comparable to age-matched controls. This observation is consistent with the findings of Patel et al. (1987) that recovery of CAT occurs in basal forebrain projection regions, specifically the hippocampus and neocortex, following cessation of PTU treatment in animals given that drug during development. Although recovery of CAT activity was noted in target areas of basal forebrain neurons, CAT levels in the basal forebrain itself

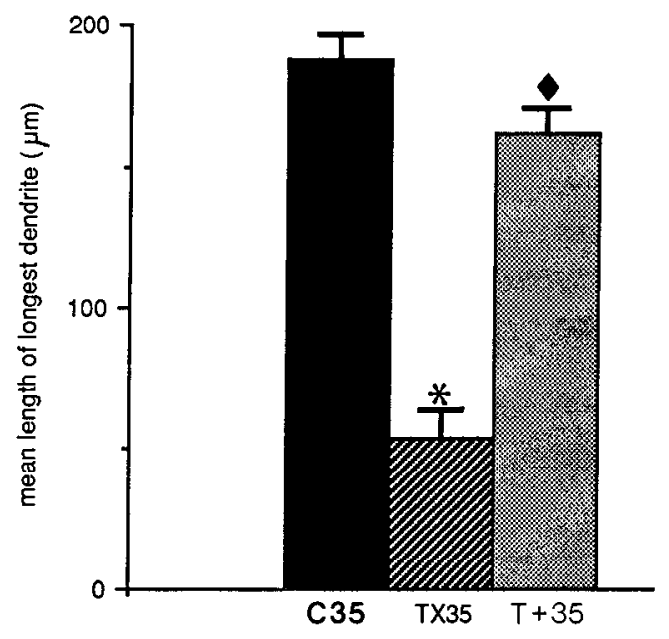

Figure 14. Effects of hypothyroidism (TX35) or hyperthyroidism $(\mathrm{T}+35)$ on length of the longest dendrite in nucleus basalis neurons at age P35. Asterisk and diamond signify statistically significant difference $(p<0.001$ and $p<0.05$, respectively) from euthyroid control (C35). Each bar value is based on data from 4 animals. Vertical error lines indicate SEM.

failed to return to normal levels (Patel et al., 1987). In this report, we have shown recovery of CAT immunoreactivity in nucleus basalis neurons despite continued PTU treatment. A possible explanation for these seemingly inconsonant findings is that Patel et al. (1987) included striatal tissue in their "basal forebrain" samples. The lack of CAT recovery by these latter investigators, therefore, might be due to a more permanent effect of hypothyroidism on the cholinergic enzyme in striatal tissue, a phenomenon previously reported by Kalaria and Prince (1985a). We have also observed a decrease in CAT immunoreactivity in striatal cells and neuropil that does not return to normal with the passage of time (Gould, 1988). Since CAT immunoreactivity in the basal forebrain recovered despite continued PTU treatment, it is likely that thyroid hormone is not the only factor contributing to the expression of this enzyme in basal forebrain neurons. Both estradiol and NGF have been demonstrated to increase CAT activity in the developing septohippocampal system (Hefti et al., 1984; Luine, 1985), for example, indicating that developmental increases in CAT in basal forebrain neurons could result from a number of available factors. Some evidence suggests that the effects of T3 and NGF on cultures of basal forebrain neurons are similar but work through different mechanisms (Hefti et al., 1986; Hayashi and Patel, 1987; Patel et al., 1988). Because thyroid hormone has been shown to directly influence the differentiation of astroglia (Aizenman and de Vellis, 1987), it is also conceivable that the thyroid hormone effects we observed for cholinergic basal forebrain neurons reflected a dependence on glial factors. Indeed, NGF effects on cholinergic neurons can be augmented by astroglia (Hartikka and Hefti, 1988), which strongly implicates glial cell mediation of thyroid hormone-NGF interactions.

The present findings indicate that CAT expression in cholinergic PMT neurons is not affected by hypothyroidism or by T3, the latter result being consistent with the observations of Honegger and Lenoir (1980) that telencephalic cultures respond to thyroid hormone with more dramatic increases in CAT than is observed for whole brain cultures. Available evidence indicates that PMT neurons, in contrast to basal forebrain neurons, are 

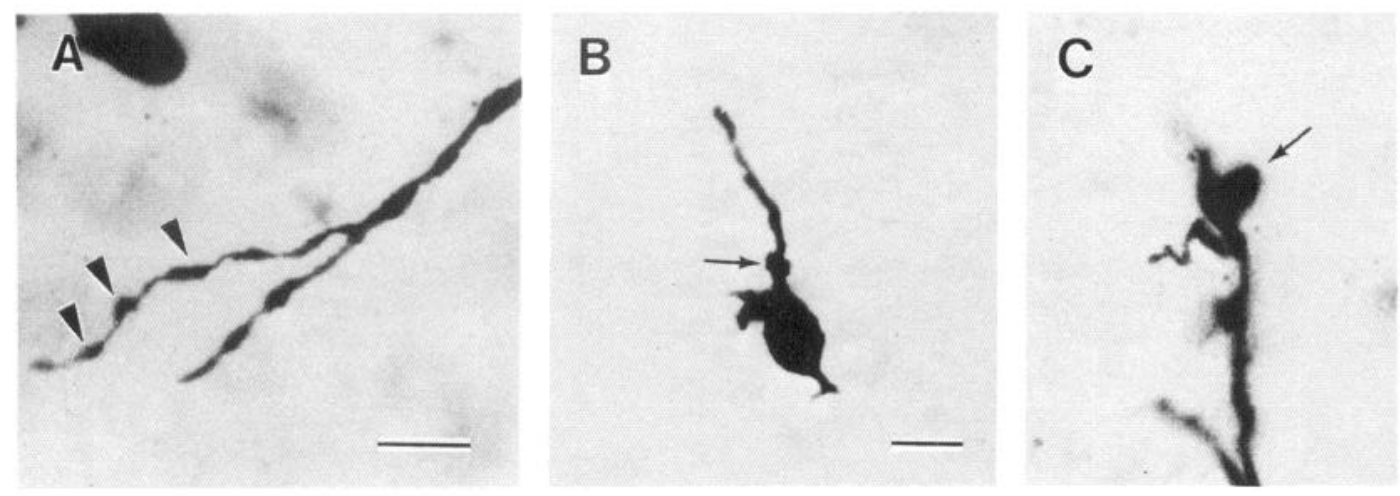

Figure 15. Golgi-impregnated neurons in nucleus basalis from $\mathrm{P} 18(A)$ and $\mathrm{P} 35(B, C)$ hypothyroid brains in a single plane of focus. The entire extents of these neurons in a single section, designated by the same letters, are shown in Figure 16. The arrowheads in $A$ point to dendrites with features characteristic of normal nucleus basalis neurons (compare with cells in Fig. 6). Arrows indicate morphologic entities not typically encountered in euthyroid controls (see Fig. 6). Scale bar in $B$ is $15 \mu \mathrm{m}$. Scale bar in $A$ is $10 \mu \mathrm{m}$ and applies also to $C$.

also not sensitive to NGF (Richardson et al., 1986; Woolf et al., 1989), and the present observations suggest a further difference between cholinergic basal forebrain and PMT neurons, namely their sensitivity to thyroid hormone manipulations. In addition, chronic hyperthyroidism, which resulted in eventual loss of CAT-positive cells in the basal forebrain, appeared to have no effect on PMT cholinergic neurons. This lack of response of PMT neurons to the seemingly degenerative effects of hyperthyroidism suggests that $\mathrm{T} 3$ treatment does not produce generalized neuropathologies in the brain but, rather, targets particular neuronal populations.

\section{Thyroid hormone effects on the morphology of cholinergic neurons}

It is likely that the Golgi-impregnated neurons we analyzed were cholinergic, not only because of the stringent morphological criteria imposed in the present experiments but also because the vast majority of the neurons in the nucleus basalis, approximately $90 \%$, are immunoreactive for CAT in the normal brain (Mesulam et al., 1983). Furthermore, hypothyroidism, as well as hyperthyroidism, did not alter the number of CAT-positive neurons in this brain region during the time period when Golgi analyses were performed.

The present results suggest that cholinergic basal forebrain neurons may rely on thyroid hormone for the normal overshoot in cell body size and for the development of normal dendritic profiles. The observations that hypothyroidism prevents somal hypertrophy and that hyperthyroidism hastens cell body hypertrophy are compatible with the conjecture that the normal overshoot in perikaryal size is controlled, at least in part, by thyroid hormone. It has been suggested that the critical period for thyroid hormone action in the euthyroid developing rat is between P14 and P35 (Eayrs, 1964). This time corresponds roughly to the period when large increases and subsequent decreases in basal forebrain cell body size occur (Butcher et al., 1988; Gould et al., 1989). The premature increase in cell body size in the basal forebrain of hyperthyroid animals suggests that excess thyroid hormone accelerates normal developmental phenomena in this cell group. The observation that these same neurons attain an even greater size than normal basal forebrain neurons and undergo a more rapid period of cell body shrinkage, however, suggests that hyperthyroidism, at least when produced according to procedures used in this laboratory, does not result in a synchronized shift of a normal developmental occurrence. It remains possible, however, that smaller doses of T3 might result in an accelerated occurrence of authentically normal developmental phenomena.

The dendritic architecture of basal forebrain neurons raised in a dysthyroid state also suggests that hyperthyroidism or hypothyroidism does not merely hasten or slow, respectively, the normal sequence of morphological development. Hyperthyroidism results in basal forebrain neurons with an increased number of primary dendrites and an increased number of dendritic branchpoints as compared to age-matched controls at both P18 and P35. The dendritic outgrowths observed with hyperthyroid neurons were somewhat similar to those observed for the control neurons described in this report (see also Dinopoulos et al., 1988), but those outgrowths were longer and more numerous and extended from perikarya as well as proximal and distal dendrites. The observations of perisomal and dendritic filopodia that persist into adulthood and the presence of fine outgrowths from cholinergic fibers in target regions suggest that chronic treatment with thyroid hormone results in basal forebrain neurons with abnormal morphological features.

Our findings with prolonged PTU administration suggest that hypothyroidism prevents the normal development of the number of primary dendrites, the number of dendritic branchpoints, and the length of dendrites. By P35, however, nucleus basalis neurons from hypothyroid brains did not differ from P35 con-

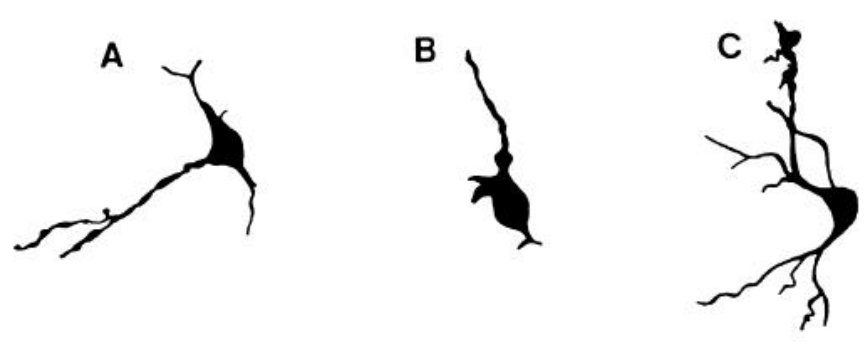

Figure 16. Camera lucida drawings of the nucleus basalis neurons depicted in part in Figure 15. Observe the meagre and sometimes abnormal dendritic arbors (compare with neurons in Figs. 6 and 8). Scale bar is $30 \mu \mathrm{m}$ and applies to all neurons. 
trols with respect to number of primary dendrites and number of dendritic branchpoints. These quantative measures could suggest a trend toward normal adult profiles in the hypothyroid animal with increasing age, but there was no corresponding evidence suggesting an increase in the mean length of the longest dendrite. Furthermore, many of these neurons possessed aberrant dendritic protuberances as late as P35 that were never observed on normal basal forebrain neurons. The observation that cell body size remained substantially diminished at the latest time period examined further suggests that basal forebrain neurons raised in a hypothyroid state do not attain normal morphologies during the passage of time.

Thyroid hormone has been demonstrated to affect morphological characteristics of several other neuronal populations, including cerebellar Purkinje cells (Legrand, 1977; Morreale de Escobar et al., 1983), dopaminergic hypothalamic neurons (Puymirat et al., 1983), and pyramidal cells of the neocortex (Ipina et al., 1987) and hippocampus (Rami et al., 1986). Nonetheless, the lack of apparent effect of thyroid hormone on the development of cholinergic PMT neurons suggests that thyroid hormone can influence specific neuronal configurations, including selected cells within categories of neurons having the same transmitter phenotype.

\section{Functional considerations}

A dysthyroid state during the critical period of development leads to profound and lasting behavioral abnormalities (Eayrs, 1964; Macfaul et al., 1978). Among the most commomnly noted functional abnormalities associated with a hypothyroid or hyperthyroid developmental state are learning and memory deficits (Eayrs, 1964; Mäenpää, 1972; Macfaul et al., 1978). It is possible, therefore, that brain regions that are involved in learning and memory are particularly sensitive during development to thyroid hormone. Several lines of evidence suggest that the cholinergic basal forebrain plays a role in learning and memory (Collerton, 1986; Hepler et al., 1985; Salazar et al., 1986; Miyamoto et al., 1987). Biochemical studies (Hefti et al., 1986; Hayashi and Patel, 1987; Patel et al., 1987) and the immunohistochemical and morphological data presented in this report suggest that cholinergic basal forebrain neurons are dramatically affected by abnormal levels of thyroid hormone during development. These morphological and chcmical abbcrations may represent a major cause of the learning and memory deficits that result from developmental hyperthyroidism or hypothyroidism. It is unlikely that the delay in CAT appearance observed with hypothyroidism significantly contributes to permanent memory impairment, since normal levels appear to be attained with time. The morphological alterations, however, did nol show any trend toward recovery during the time period examined, and these possibly permanent morphological changes could contribute significantly to enduring learning and memory deficits. Stunted dendrites and decreased perikaryal sizes in the basal forebrain of hypothyroid animals would substantially diminish the membrane area available for receiving synaptic inputs. Furthermore, abnormal and excessive numbers of dendrites observed in cholinergic basal forebrain neurons of hyperthyroid animals could dramatically change the pattern of afferent input to those cells. Premature cell body hypertrophy and CAT increases could also alter the sequence of developmental events necessary for the formation of appropriate afferent or efferent connections. Collectively, the developmental ab- normalities resulting from hypothyroidism or hyperthyroidism might prevent the adequate functioning of certain systems (e.g. the cholinergic basal forebrain) necessary for learning and memory formation.

\section{Deleterious effects of chronic thyroid hormone treatment}

The significant decrease in the number and cell body sizes of cholinergic nucleus basalis neurons of hyperthyroid brains, observed at the latest time periods examined, suggests that chronic treatment with T3 produces eventual degeneration in this neuronal population but only after relatively long periods of exposure. Since hyperthyroid brains at earlier time periods showed excessive dendritic and perisomatic growth, it is conceivable that a phase of aberrant neuronal proliferation leads into and perhaps contributes directly to degenerative mechanisms. In this regard, it is noteworthy that morphological profiles indicative of abnormal neuronal growth have been reported in neural regions where cellular degeneration is also observed in the brains of Alzheimer's disease (Arendt et al., 1986) and Down's syndrome patients (Marin Padilla, 1972; Fabregues and Ferrer, 1983), as well as in the normally aging nervous system (Coleman and Flood, 1986). The most common explanation of these cytoarchitectural aberrations embraces the notion that growth occurs in certain healthy neurons to compensate for the death of neighboring cells (Coleman and Flood, 1986). Although this conjecture may suffice for some situations, such a hypothesis cannot explain the results presented in this report for nucleus basalis. Because a developmental study was performed examining several postnatal time periods, it cannot be argued that degeneration preceded morphological indicators of neuronal growth.

Since there is a paucity of available information concerning the presence or absence of thyroid hormone receptors on cholinergic basal forebrain neurons, it is difficult to assess whether or not the detrimental effects of T3 treatment were mediated through other hormones or growth factors. Hyperthyroidism has been demonstrated to increase blood levels of glucocorticoids and other indices of the hypothalamic-pituitary-adrenal axis (Poland et al., 1979; D'Agostino and Henning, 1982; Henning et al., 1986), and some evidence suggests that glucocorticoids stimulate cholinergic markers in the forebrain (Riker et al., 1979). These findings present the possibility that hyperthyroidism influences cholinergic neurons in nucleus basalis by direct effects on glucocorticoids. A recent study has shown that short-term glucocorticoid treatment results in hippocampal neurons with increased numbers of protein synthesis-related organelles (Miller et al., 1988). Chronic treatment with glucocorticoids, on the other hand, produces acceleration of age-related degeneration in the hippocampus (Sapolsky et al., 1985). Collectively, these results suggest that a period of growth precedes neuronal degeneration in this latter model as well.

The frequency of hypercortisolism, as well as thyroid abnormalities, also appears to increase with advancing age (Sapolsky et al., 1987; Spaulding, 1987) and are more common in Alzheimer's disease patients than in control individuals (Sapolsky et al., 1987; Heyman et al., 1983, 1984). Since the hippocampus and the cholinergic basal forebrain are both significantly affected in aging and age-related dementias (Collerton, 1986), increased understanding of the interactive and independent roles these hormones play in the development, maintenance, and senescence of neurons in these brain regions would appear critical. 


\section{References}

Aizenman, Y., and J. de Vellis (1987) Synergistic action of thyroid hormone, insulin and hydrocortisone on astrocyte differentiation. Brain Res. 414: 301-308.

Arendt, T., H. G. Zvegintseva, and T. A. Leontovich (1986) Dendritic changes in the basal nucleus of Meynert and in the diagonal band nucleus in Alzheimer's disease-A quantitative Golgi investigation. Neuroscience 19: 1265-1278.

Atterwill, C. K., A. Kingsbury, J. Nicholls, and A. Prince (1984) Development of markers for cholinergic neurones in re-aggregate cultures of foctal rat whole brain in serum-containing and serum-free media: Effects of triiodothyronine (T3). Br. J. Pharmacol. 83: 89-102.

Bigl, V., N. J. Woolf, and L. L. Butcher (1982) Cholinergic projections from the basal forebrain to frontal, parietal, temporal, occipital, and cingulate cortices: A combined fluorescent tracer and acetylcholinesterase analysis. Brain Res. Bull. 8: 727-749.

Brauer, K., and E. Winkelmann (1987) Cells with varicose dendrites: A characteristic type of neurons in Golgi preparations of the rat cholinergic basal forebrain nuclei. J. Hirnforsch. 28: 117-123.

Browning, T. B., R. W. Atkins, and H. Weiner (1954) Cerebral metabolic disturbances in hypothyroidism. Arch. Intern. Med. 93: 938950.

Butcher, L. L., E. Gould, and N. J. Woolf (1985) Morphologic characteristics of central cholinergic neurons in the rat. Soc. Neurosci. Abstr. 11: 1238.

Butcher, L. L., E. Gould, T. W. Farris, and N. J. Woolf (1988) Development of brain cholinergic systems. Soc. Neurosci. Abstr. 14: 633.

Coleman, P. D., and D. G. Flood (1986) Dendritic proliferation in the aging brain as a compensatory repair mechanism. Prog. Brain Res. 70: 227-237.

Collerton, D. (1986) Cholinergic function and intellectual decline in Alzheimer's disease. Neuroscience 19: 1-28.

D'Agostino, J., and S. J. Henning (1982) Role of thyroxine in coordinate control of corticosterone and $\mathrm{CBG}$ in postnatal development. Am. J. Physiol. 242: E33-E39.

Dinopoulos, A., J. G. Parnavelas, H. B. M. Uylings, and C. G. Van Eden (1988) Morphology of neurons in the basal forebrain of the rat: A Golgi study. J. Comp. Neurol. 272: 461-474.

Eayrs, J. T. (1964) Endocrine influence on cerebral development. Arch. Biol. 75: 529-565.

Eckenstein, F., and H. Thoenen (1982) Production of specific antisera and monoclonal antibodies to choline acetyltransferase: Characterization and use for identification of cholinergic neurons. EMBO J. 1: 363-368.

Fabregues, I., and I. Ferrer (1983) Abnormal perisomatic structures in non-pyramidal neurons in the cerebral cortex in Down's syndrome. Neuropathol. Appl. Neurobiol. 9: 165-170.

Gabbott, P. L., and J. Somogyi (1984) The "single" section Golgiimpregnation procedure: Methodological description. J. Neurosci. Methods 11: 221-230.

Gorman, L. K., T. W. Farris, N. J. Woolf, and L. L. Butcher (1987) Golgi staining and choline acetyltransferase immunohistochemistry on the same brain section. Soc. Neurosci. Abstr. 13: 776.

Gould, E. (1988) The Effects of Thyroid Hormone on the Development of Brain Cholinergic Neurons. Doctoral Dissertation, UCLA, Los Angeles, California.

Gould, E., and L. L. Butcher (1987) Transient expression of choline acetyltransferase-like immunoreactivity in Purkinje cells of the developing rat cerebellum. Dev. Brain Res. 34: 303-306.

Gould, E., T. W. Farris, and L. L. Butcher (1989) Basal forebrain neurons undergo somatal and dendritic remodeling during postnatal development: A single-section Golgi and choline acetyltransferase analysis. Dev. Brain Res. 46: 297-302.

Hartikka, J, and F. Hefti (1988) Comparison of nerve growth factor's effects on development of septum, striatum and nucleus basalis cholinergic neurons in vitro. J Neurosci Res. 21: 352-364.

Hayashi, M., and A. J. Patel (1987) An interaction between thyroid hormone and nerve growth factor in the regulation of choline acetyltransferase activity in neuronal cultures, derived from the septaldiagonal band region of the embryonic rat brain. Dev. Brain Res. 36: 109-120.

Hays, W. L. (1981) Statistics. Holt, Rinehart and Winston, New York.

Hefti, F., A. Dravid, and J. Hatikka (1984) Chronic intraventricular injections of nerve growth factor elevate hippocampal choline acetyltransferase activity in adult rats with partial septohippocampal lesions. Brain Res. 293: 305-311.

Hefti, F., J. Hartikka, and M. B. Bolger (1986) Effect of thyroid hormone analogs on the activity of choline acetyltransferase in cultures of dissociated septal cells. Brain Res. 375: 413-416.

Henning, S. J., L. L. Leeper, and D. N. Dieu (1986) Circulating corticosterone in the infant rat: The mechanism of age and thyroxine effects. Pediatr. Res. 20:87-92.

Hepler, D. J., G. L. Wenk, B. L. Cribbs, D. S. Olton, and J. T. Coyle (1985) Memory impairments following basal forebrain lesions. Brain Res. 346: 8-14.

Heyman, A., W. E. Wilkinson, B. J. Hurwitz, D. Schmechel, A. H. Sigmon, T. Weinberg, M. J. Helms, and M. Swift (1983) Alzheimer's disease: Genetic aspects and associated clinical disorders. Ann. Neurol. 14: 507-515.

Heyman, A., W. E. Wilkinson, J. A. Stafford, M. J. Helms, A. H. Sigmon, and T. Weinberg (1984) Alzheimer's disease: A study of epidemiological aspects. Ann. Neurol. 15: 335-341.

Honegger, P. (1983) Nerve growth factor-sensitive brain neurons in culture. Monogr. Neural Sci. 9: 36-42.

Honegger, P., and D. Lenoir (1980) Triiodothyronine enhancement of neuronal differentiation in aggregating fetal rat brain cells cultured in a chemically defined medium. Brain Res. 199: 425-434.

Ipina, S. L., A. Ruiz-Marcos, F. Escobar del Rey, and G. Morreale de Escobar (1987) Pyramidal cortical cell morphology studied by multivariate analysis: Effects of neonatal thyroidectomy, aging and thyroxine-substitution therapy. Dev. Brain Res. 37: 219-229.

Kalaria, R. N., and A. K. Prince (1985a) Effects of thyroid deficiency on the development of cholinergic, GABA, dopaminergic and glutamate neurons markers and DNA concentrations in the rat corpus striatum. Int. J. Dev. Neurosci. 3: 655-666.

Kalaria, R. N., and A. K. Prince (1985b) The effects of neonatal thyroid deficiency on acetycholine synthesis and glucose oxidation in rat corpus striatum. Dev. Brain Res. 20: 271-279.

Kalaria, R. N., A. M. Kotas, A. K. Prince, R. Reynolds, and P. T-H. Wong (1981) Choline uptake and choline acetyltransferase in brain of developing rats made hypothyroid with propylthiouracil. In Cholinergic Mechanisms: Phylogenetic Aspects, Central and Peripheral Synapses, and Clinical Significance, G. Pepeu and H. Ladinsky, eds., pp. 73-83, Plenum, New York.

Kaltenbach, J. C. (1953) Local action of thyroxin on amphibian metamorphosis. I. Local metamorphosis in Rana pipiens larvae affected by thyroxin-cholesterol implants. J. Exp. Zool. 122: 21-39.

Kollros, J. J., and V. M. McMurray (1956) The mesencephalic V nucleus in anurans. II. The influence of thyroid hormone on cell size and cell number. J. Exp Zool. 131: 1-26.

Kristt, D. A., R. A. McGowan, N. Martin-MacKinnon, and J. Solomon (1985) Basal forebrain innervation of rodent neocortex: Studies using acetylcholinesterase histochemistry, Golgi and lesion strategies. Brain Res. 337: 19-39.

Legrand, J. (1977) Morphologic and biochemical effects of hormone on the developing nervous system in mammals. In Brain: Fetal and Infant: Current Research on Normal and Abnormal Development, $\mathrm{S}$. R. Berenberg, ed., pp. 137-164, Nijhoff, The Hague, Netherlands.

Luine, V. N. (1985) Estradiol increases choline acetyltransferase activity in specific basal forebrain nuclei and projection areas of female rats. Exp. Neurol. 89: 484-490.

Macfaul, R., S. Dorner, E. M. Brett, and D. B. Grant (1978) Neurological abnormalities in patients treated with hypothyroidism from early life. Arch. Dis. Child. 53: 611-619.

Mäenpää, J. (1972) Congenital hypothyroidism: Aetiological and clinical aspects. Arch. Dis. Child. 47: 914-923.

Marin Padilla, M. (1972) Structural abnormalities of the cerebral cortex in human chromosomal aberrations. A Golgi study. Brain Res. 44: 625-629.

Meaney, M. J., D. H. Aitken, and R. M. Sapolsky (1987) Thyroid hormones influence the development of hippocampal glucocorticoid receptors in the rat: A mechanism for the effects of postnatal handling on the development of the adrenocortical stress response. Neuroendocrinology 45: 278-283.

Mesulam, M.-M., E. J. Mufson, B. H. Wainer, and A. I. Levey (1983) Central cholinergic pathways in the rat: An overview based on an alternative nomenclature (Ch1-Ch6). Neuroscience 10: 1185-1201. Miller, M. M., E. Antecka, and R. Sapolsky (1988) Acute effects of 
corticosterone on rat hippocampal perikarya. Soc. Neurosci. Abstr. 14: 1323 .

Miyamoto, M., J. Kato, S. Narumi, and A. Nagaoka (1987) Characteristics of memory impairment following lesioning of the basal forebrain and medial septal nucleus in rats. Brain Res. 419: 19-31.

Morreale de Escobar, G., F. Escobar dcl Rcy, and A. Ruiz-Marcos (1983) Thyroid hormone and the developing brain. In Congenital Hypothyroidism, J. H. Dussault and P. Walker, eds., pp. 85-127, Marcel Dekker, New York.

Patel, A. J., M. Hayashi, and A. Hunt (1987) Selective persistent reduction in choline acetyltransferase activity in basal forebrain of the rat after thyroid deficiency during early life. Brain Res. 422: 182185.

Patel, A. J., M. Hayashi, and A. Hunt (1988) Role of thyroid hormone and nerve growth factor in the development of choline acetyltransferase and other cell-specific marker enzymes in the basal forebrain of the rat. J. Neurochem. 50:803-811.

Poland, R. E., M. E. Weichsel, and R. T. Rubin (1979) Postnatal maturation patterns of serum corticosterone and growth hormone: Effect of chronic thyroxine administration. Horm. Metabol. Res. 11: 222-227.

Rami, A., A. J. Patel, and A. Rabie (1986) Thyroid hormone and development of the rat hippocampus: Morphological alterations in granule and pyramidal cells. Neuroscience 19: 1217-1226.

Richardson, P. M., V. M. K. Verge Issa, and R. J Riopelle (1986) Distribution of neuronal receptors for nerve growth factor in the rat. J. Neurosci. 6: 2312-2321.
Salazar, A. M., J. Grafman, S. Schlesselman, S. C. Vance, J. P. Mohr, M. Carpenter, P. Pevsner, C. Ludlow, and H. Weingartner (1986) Penetrating war injuries of the basal forebrain: Neurology and cognition. Neurology 36: 459-465.

Sapolsky, R. M., L. C. Krey, and B. S. McEwen (1985) Prolonged glucocorticoid exposurc reduccs hippocamal ncuron number: Implications for aging. J. Neurosci. 5: 1222-1227.

Sapolsky, R., M. Armanini, D. Pakan, and T. Rombaugh (1987) Stress and glucocorticoids in aging. Endocrinol. Metabol. Clin. 16: 965-980.

Sokoloff, L. (1977) Biochemical mechanisms of the action of thyroid hormones: Relationship to their role in brain. In Thyroid Hormones and Brain Development, G. D. Grave, ed., pp. 73-91, Raven Press, New York.

Spaulding, S. W. (1987) Age and the thyroid. Endocrinol. Metabol. Clin. 16: 1013-1025.

Valcana, T. (1971) Effects of neonatal hypothyroidism on the development of acetylcholinesterase and choline acetyltransferase activities in rat brain. In Influence of Hormones on the Nervous System, D. H. Ford, ed., pp. 174-184, S. Karger, Basel.

Woolf, N. J., and L. L. Butcher (1986) Cholinergic systems in the rat brain: III. Projections from the pontomescencephalic tegmentum to the thalamus, tectum, basal ganglia, and basal forebrain. Brain. Res. Bull. 16: 603-637.

Woolf, N. J., E. Gould, and L. L. Butcher (1989) Nerve growth factor receptor is associated with cholinergic neurons of the basal forebrain but not the pontomesencephalon. Neuroscience 30:143-152. 